\title{
Sistem informasi pelaksana program keluarga harapan (PPKH) kabupaten agam berbasis web
}

\author{
Elmawati $\left.{ }^{1}\right)$, Veni Wedyawati $\left.{ }^{2}\right)$, Insanul Fikri ${ }^{3}$ ) \\ ${ }^{123}$ Sekolah Tinggi Teknologi Industri Padang, Jl. Prof Dr. Hamka No. 121 Tabing, Padang, Indonesia \\ elmawati@sttind.ac.id ${ }^{1)}$, veniwedyawati@sttind.ac.id ${ }^{2)}$, infikri77@gmail.com ${ }^{3)}$
}

\begin{abstract}
ABSTRAK
Sistem informasi yang menarik, cepat dan tepat sangat membantu masyarakat dalam mendapatkan informasi seputaran Kegiatan Pelaksana Program Keluarga Harapan (PPKH) Kabupaten Agam. Sistem yang digunakan selama ini untuk mempublikasikan adalah secara manual, foto kegiatan dicetak dan ditempel pada dinding kosong Dinas Sosial Kabupaten Agam. Tujuan dari penelitian sistem informasi Pelaksana Program Keluarga Harapan (PPKH) ini untuk merancang sistem informasi Pelaksana Program Keluarga Harapan (PPKH) Kabupaten Agam berbasis web sesuai dengan kebutuhan dan menerapkan sistem ini dengan bahasa pemograman PHP dan MySQL. Metode yang dipakai dalam perancangan sistem ini adalah metode pengembangan sistem SDLC dengan tujuh (7) siklus yaitu perencanaan sistem, analisis sistem, perencanaan sistem secara umum, desain sistem, evaluasi sistem, implementasi sistem dan pemeliharaan sistem. Perancangan Sistem Informasi ini dapat mengatasi kendala yang selama ini dialami PKKH Kabupaten Agam dalam mempublikasikan kegiatan Program Keluarga Harapan lebih efektif. Dengan adanya Sistem Informasi Pelaksana Program Keluarga Harapan ini dapat memberikan kemudahan bagi Pelaksana Program Keluarga Harapan (PPKH) untuk mempublikasikan kegiatan-kegiatan yang selama ini belum terpublikasi dijaringan internet. Sistem informasi Pelaksana Program Keluarga Harapan (PPKH) Kabupaten Agam berbasis PHP dan MySQL dapat menyimpan file dokumen dan foto yang diupload apabila sewaktu-waktu dibutuhkan.
\end{abstract}

Kata kunci:Sistem Informasi, PPKH, PHP, MySQL

\begin{abstract}
An Interesting, fast and appropriate information system, will fully help people to get an important information about all Program Keluarga Harapan (PKH) activities in Agam regency. Before, the system manually is used to publish printed all activities pictures that are pasted in the Agam regency social department empty wall. The goal of the system information research is to design a system information based web as appropriate needed and it is aplied PHP and MySQL programmed language and the system will be used to sharing Agam program keluarga harapan activities. The method that is applied in the system design is SDLC developed system method which has seven cycles; system plan, system analisys, general system plan, system design, system evaluation, system implementation, and system maintenance. The information system design hopefully can solve uneffective publishing problem that has been facing by PPKH Agam before. By the existance of the system in PKH, it grant simplicity to users (PPKH) to publish all unexpose activities in internet before. PPKH Agam system information which is based on SQL and PHP can save aploaded documents and photoes and also can be downloaded whenever they are needed.
\end{abstract}

Keywords: Information System, PPKH, PHP, MySQL

diunggah: Oktober 2021, direvisi: November 2021, diterima: Desember 2021, dipublikasi: Desember 2021 Copyright (c) 2021 Elmawati, Veni Wedyawati, Insanul Fikri

This is an open access article under the CC-BYlicense

\section{PENDAHULUAN}

Seiring berkembangnya sistem informasi minat dan penggunaan komputer dimasa sekarang ini. Semua bidang harus memiliki pengiriman yang cepat dan akurat. Untuk itu penggunaan sebuah informasi yang telah diintegrasikan dengan penggunaan komputer makin 
banyak digunakan. Banyak lembaga pemerintah, organisasi, atau perusahaan bekerja dengan baik teknologi komputer dalam membantu proses kerja mereka.Sehingga kehadirannya memberikandampak luar biasa dalam kemudahan manusia dalam menyelesaikan setiap pekerjaan khususnya dalam kegiatan pendataan. (Bathin \& Ramayanti, 2019)

Perancangan sistem informasi dapat dilakukan dengan menggunakan beberapa bahasa pemrograman diantaranya Microsoft Visual Basic.Net, Database MySQL. (Elmawati et al., 2020)

Kemiskinan merupakan satu daribanyak masalah yang menjadi perhatianhampir disetiap negara, tak terkecuali diIndonesia. Kemiskinan juga merupakanmasalah sosial yang senantiasa relevan untuk dikaji secara berkelanjutan Dalam perkembangannya, upaya penurunan angka kemiskinan sudahdilakukan dalam banyak program oleh pemerintah. Dari sejumlah program yang telahdilaksanakan oleh pemerintah itu, penulisakan mengkaji tentang Program Keluarga Harapan (PKH). (Alsukri, 2020)

Pelaksana Program Keluarga Harapan (PPKH) Kabupaten Agam yang bersekretariat di Dinas Sosial Kabupaten Agam belum mempunyai website sendiri untuk memberikan informasi seputaran Program Keluarga Harapan terkhususnya informasi kegiatan-kegiatan pendamping PKH dilapangan dengan para peserta Program Keluarga Harapan, koordinsai dengan instansi terkait seperti Wali Jorong dan wali nagari serta verifikasi fasdik ke sekolahsekolah dari tingkat SD,SMP,SMA dan faskes ke puskesmas atau pustu (puskesmas pembantu) dalam kegiatan pemeriksanaan bagi ibu hamil dan balita (bayi di bawah lima tahun) yang ada di kabupaten Agam.

Pelaksana Program Keluarga Harapan (PPKH) Kabupaten Agam yang bersekretariat di Dinas Sosial Kabupaten Agam belum mempunyai website sendiri untuk memberikan informasi seputaran Program Keluarga Harapan terkhususnya informasi kegiatan-kegiatan pendamping PKH dilapangan dengan para peserta Program Keluarga Harapan, koordinsai dengan instansi terkait seperti Wali Jorong dan wali nagari serta verifikasi fasdik ke sekolahsekolah dari tingkat SD, SMP, SMA dan faskes ke puskesmas atau pustu (puskesmas pembantu) dalam kegiatan pemeriksanaan bagi ibu hamil dan balita (bayi di bawah lima tahun) yang ada di kabupaten Agam.

Website yang menarik, cepat dan akurat merupakan cara yang tepat bagi masyarakat untuk mendapatkan informasi tentang kegiatan anggotanya dan pimpinan PKH. Karena sistem yang digunakan selama ini adalah manual, maka foto-foto kegiatan tersebut dipublikasi dan dipasang di dinding Dinas Sosial Kabupaten Agam beserta uraian Kegiatan. Untuk itu diperlukan pembuatan website yang dapat diakses secara online, membantu masyarakat mencari informasi tentang Keluarga Harapan, khususnya peneliti PKH. karena kinerjanya lebih baik dari sebelumnya.

Untuk memecahkan permasalahan di atas penulis ingin membangun sebuah sistem informasi yang dapat dipublikasikan kegiatan pendamping sosial PPKH Kabupaten Agam dikalangan masyarakat umum khususnya masyarakat Kabupaten Agam. Dengan sistem informasi yang akan dibuat ini diharapkan agar dapat memahami tentang hak serta kewajiban peserta PKH. Sistem informasi ini diaplikasikan ke dalam bahasa pemrograman PHP yang akan dituangkan pada penulisan penelitian yang berjudul Sistem Informasi Pelaksana Program Keluarga Harapan (PPKH) Kabupaten Agam Berbasis Web.

\section{METODE}

Jenis penelitian yang peneliti lakukan adalah penelitian terapan (Applied research). Penelitian terapan adalah penelitian yang diarahkan untuk mendapatkan informasi yang dapat digunakan untuk memecahkan masalah. Penelitian terapan dilakukan dengan tujuan untuk menerapkan, menguji dan mengevaluasi masalah-masalah praktis sehingga dapat 
dimanfaatkan untuk kepentingan manusia baik secara individual maupun kelompok. (Wedyawati, 2019)

Selain itu dalam peneliitian penulis menggunakan juga metode deskriptif dengan pendekatan kualitatif. Melalui penggunaan metode ini peneliti dapat menggambarkan serta mengkaji objek penelitian dengan lebihspesifik dan mendetail dan dapat digunakan untuk mencari solusi atas permasalahan yang ada.(Alim, 2019)

Jenis penelitian ini adalah penelitian dan pengembangan atau Research and Development $(\mathrm{R} \& \mathrm{D})$ suatu proses pengembangan perangkat pendidikan yang dilakukan melalui serangkaian riset yang menggunakan berbagai metode dalam suatu siklus yang melewati berbagai tahapan.

Pengumpulan data mencakup data primer yang didapat dengan metode wawancara (Interview) dan metode pengamatan (Observasi).

Variabel penelitian adalah segala sesuatu yang akan menjadi objek pengamatan dalam penelitian. Variabel dalam penelitian ini, yaitu Data yang menyangkut dengan PKH Dinas Sosial kabupaten Agam.

System Development Life Cycle (SDLC)atau Siklus Hidup pengembangan Sistem adalahmetode pengembangan sistem tradisional yangdigunakan sebagian besar organisasi saat ini.SDLC adalah kerangka kerja (framework) yang terstruktur yang berisi proses-proses sekuensial dimana sistem informasi dikembangkan. (Irawan et al., 2017)

Dalam tahap ini penulis menggunakan metodologi pengambangan sistem yaitu Sistem Development Life Cycle (SDLC) yang terdiri dari 7 siklus yaitu :

1. Analisa kebutuhan.

Analisa kebutuhan merupakan tahap pertama yang menjadi dasar proses pembuatan Tailor-made software selanjutnya. Kelancaran proses pembuatan software secara keseluruhan dan kelengkapan fitur software yang dihasilkan sangat tergantung pada hasil analisa kebutuhan.(Vincensius \& Wasito, 2017)

2. Analisis sistem (Systems Analysis)

Menganalisa sistem yang lama dengan mengidentifikasi masalah, memahami masalah serta menganalisis sesuai dengan permasalahan yang ada dan menggantikan dengan sistem yang efektif.

3. Perancangan Sistem (Systems Design)

Bagian ini akan menghasilkan template dengan sejumlah fungsi lainnya, termasuk kertas yang berisi desain, template dan komponen yang dibutuhkan untuk mewujudkan desain tersebut. Setelah dilakukan analisa sistem maka selanjutnya kebutuhan yang telah didapatkan dibuat dalam bentuk rancangan agar mempermudah dalam membangun sistem.(Melinda et al., 2017). Bagian ini adalah bagian dari semua hasil pencarian dan pembahasan analisis rinci yang digunakan didalam suatu proyek atau portofolio proyek. Bagian ini dinamakan cetak biru, yaitu menyiapkan sistem yang akan dikembangkan mulai dari implementasi, dari detail sistem, hingga staf pendukung program yang akan dikembangkan.

4. Desain (perancangan) sistem terinci

Perancangan ini dilakukan dengan menjelaskan bagaimana mengimplementasikan suatu sistem ditinjau dari perangkat keras dan perangkat lunak dalam model-model yang digunakan dalam sistem.

5. Evaluasi dan Seleksi sistem

Untuk menerjemahkan atau menampilkan hasil rekayasa sistem ke dalam teknologi dimana penulis mengevaluasi dan memilih bahasa pemrograman, basis data, sistem operasi, dan spesifikasi teknis yang digunakan dalam pengembangan sistem. 
6. Implementasi (penerapan) sistem

Tahap implementasi selanjutnya adalah implementasi proyek dari tahapan sebelumnya dan pengujian. Selama implementasi, aktivitas berikut dilakukan:

a. Pembuatan Database sesuai skema rancangan.

b. Pembuatan aplikasi berdasarkan desain sistem.

c. Pengujian dan perbaikan aplikasi (debugging).

7. Pemeliharaan sistem (Maintenance)

Ini dilakukan oleh administrator yang ditunjuk untuk menjaga sistem berfungsi dengan baik berkat kemampuan sistem untuk beradaptasi sesuai kebutuhan.

Data merupakan segala keterangan mengenai variabel yang akan diteliti. Sumber datanya adalah sebagai berikut :

1. Data Primer yaitu data mengenai SDM PKH Agam dan data peserta keluarga penerima manfaat.

2. Data Sekunder yaitu berupa data yang dikumpulkan dari berbagai sumber seperti buku, jurnal serta bukti catatan atau laporan pertemuan kelompok atau Famally Development Session (FDS).

\section{HASIL DAN PEMBAHASAN}

\section{Use case diagram}

Usecase Diagram menjelaskan gambaran hubungan interaksi antara sistem dan aktor sebagaimana dapat kita lihat pada gambar 1 dibawah ini.

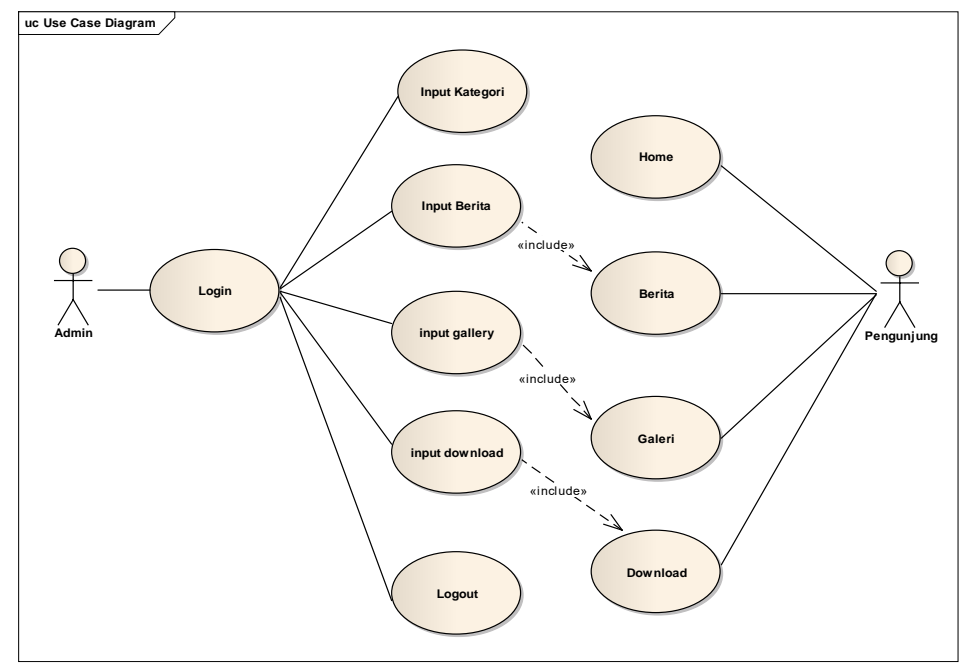

Gambar 1. Usecase diagram

\section{Menu utama}

Menu utama adalah menu awal yang ditampilkan ketika pertama kali kita mengakses website dilihat pada gambar 2 di bawah ini.

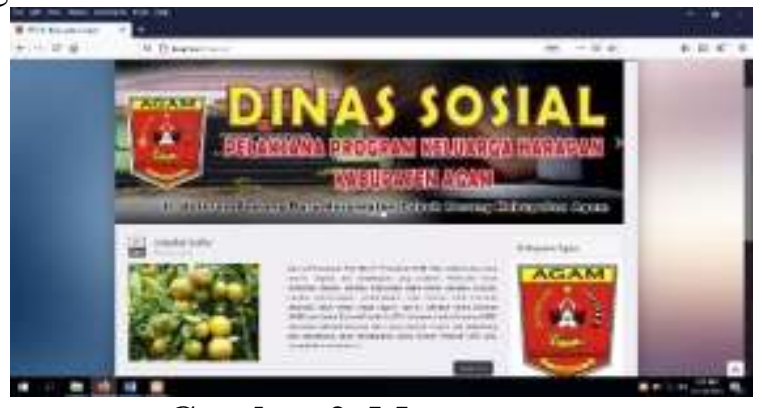

Gambar 2. Menu utama 


\section{Tampilan berita}

Tampilan berita pengunjung dapat memilih berdasarkan kategori yang telah tersedia pada website sebagaimana pada gambar 3 di bawah ini.

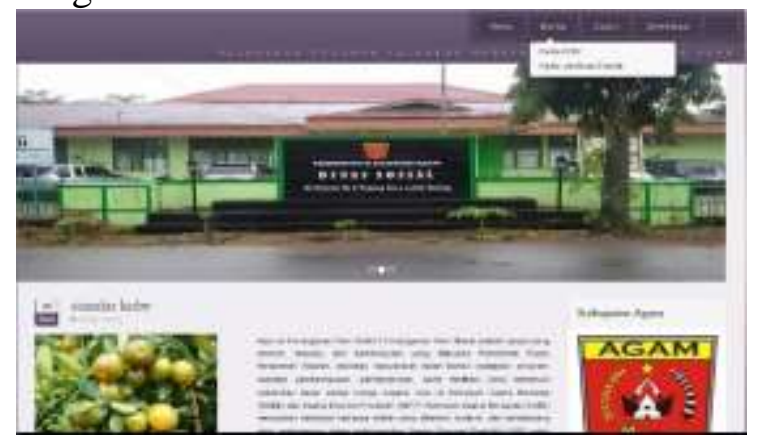

Gambar 3. Tampilan berita

\section{Tampilan gallery}

Pada Tampilan menu gallery pengunjung dapat memilih berdasarkan kategori yang telah tersedia di website dapat dilihat pada gambar 4 di bawah ini.

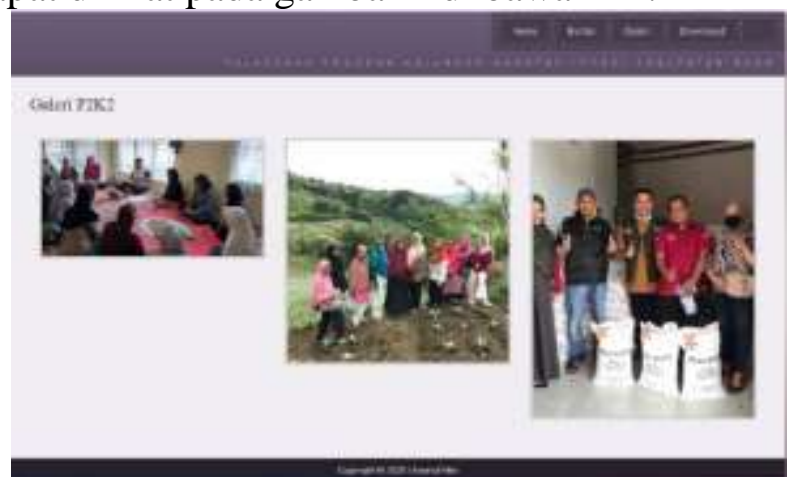

\section{Tampilan download}

\section{Gambar 4. Tampilan gallery}

Tampilan menu download pengunjung dapat memilih berdasarkan nama file yang telah tersedia pada website dapat dilihat pada gambar 5 di bawah ini.

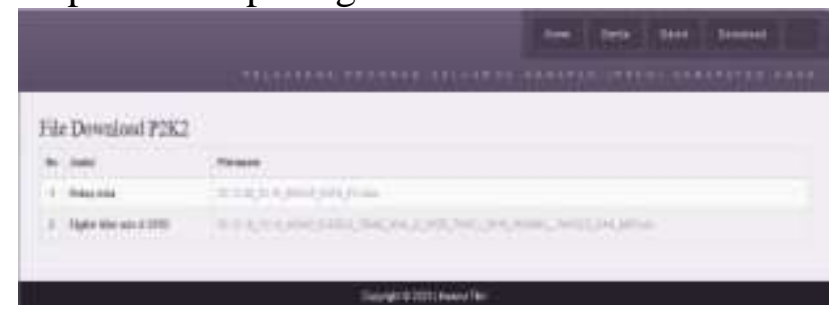

\section{Gambar 5. Tampilan download}

\section{Menu login admin}

Tampilan menu login, admin harus input nama pengguna dan kata kunci yang telah ada pada Database, terlebih dahulu agar dapat menuju kehalaman admin berikutnya dan mengelola data berita, kategori, Gallery dan download dapat dilihat pada gambar 6 di bawah ini.

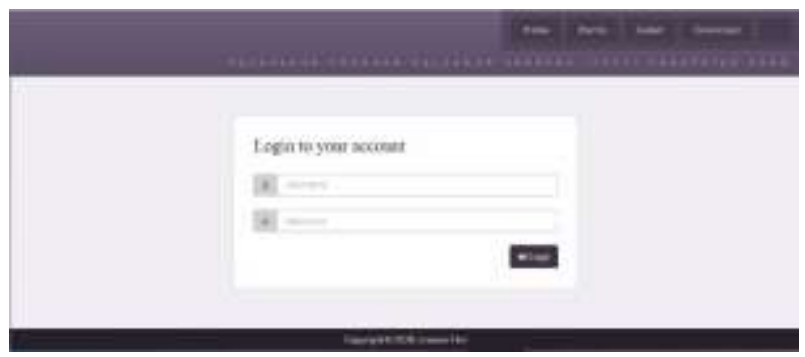

Gambar 6. Tampilan login admin 


\section{Tampilan menu admin}

Tampilan menu Admin ini merupakan pusat dari segala aktifitas-aktifitas yang dilakukan oleh admin. Seperti input admin, edit admin dan hapus admin dilihat pada gambar 7 di bawah ini.

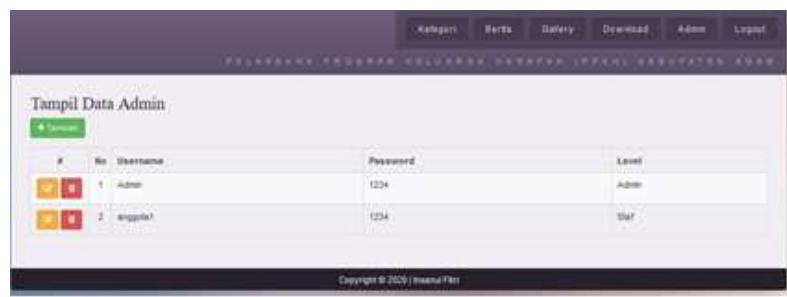

Gambar 7. Tampilan menu admin

\section{Tampilan menu kategori}

Tampilan menu Kategori ini merupakan pusat dari segala aktifitas-aktifitas yang akan dilakukan oleh admin. Seperti input kategori, edit kategori dan hapus kategori dilihat pada gambar 8 di bawah ini.

\section{Tampilan menu berita}

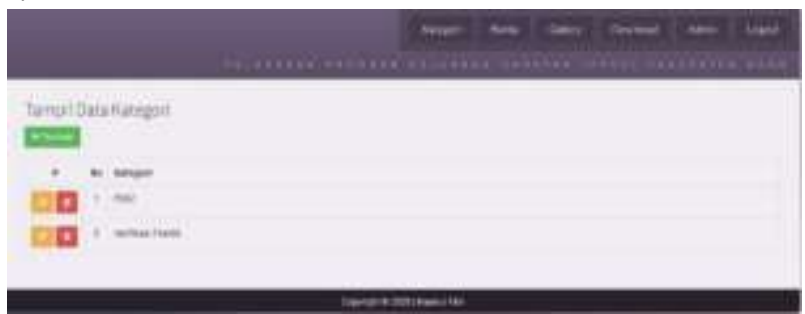

\section{Gambar 8. Tampilan menu kategori}

Tampilan menu berita ini merupakan pusat dari segala aktifitas-aktifitas yang akan dilakukan oleh admin. Seperti input berita, edit berita dan hapus berita dilihat pada gambar 9 dibawah ini.

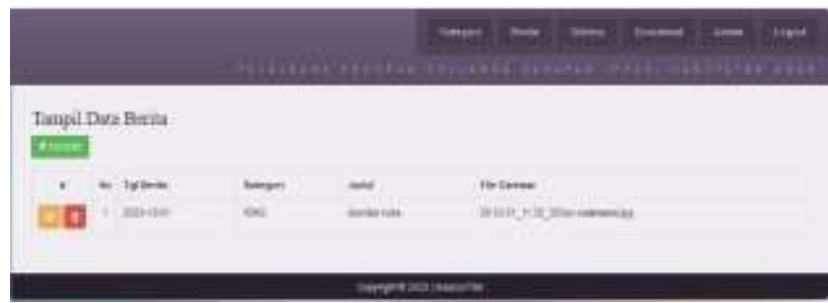

\section{Tampilan menu gallery}

\section{Gambar 9. Tampilan menu berita}

Tampilan menu gallery ini merupakan pusat dari segala aktifitas-aktifitas yang akan dilakukan oleh admin. Seperti input gallery, edit gallery dan hapus gallery dilihat pada gambar 10 di bawah ini.

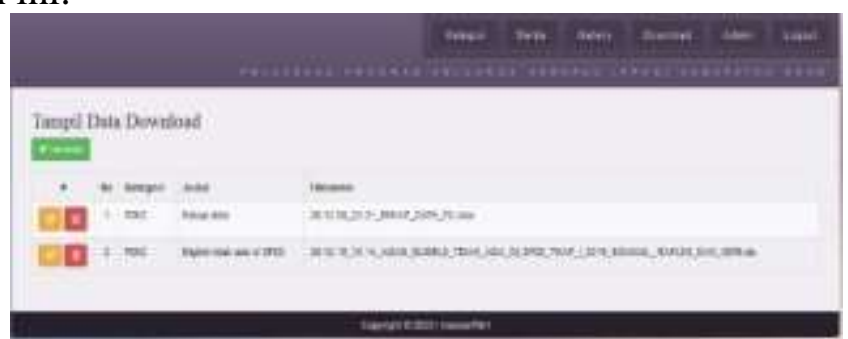

Gambar 10. Tampilan menu gallery

\section{Tampilan menu download}

Tampilan menu download ini merupakan pusat dari segala aktifitas-aktifitas yang akan dilakukan oleh admin. Seperti input download, edit download dan hapus download dilihat dibawah ini pada gambar 11 di bawah ini. 


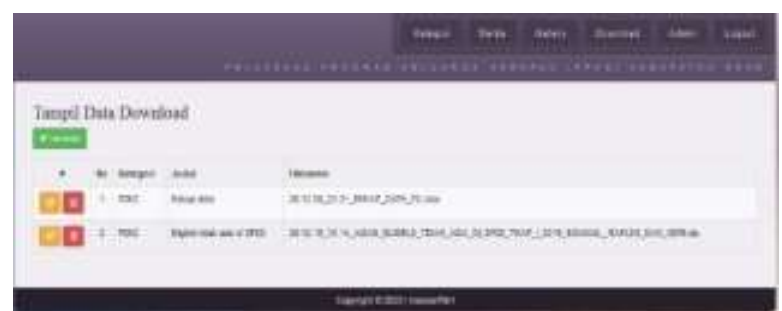

Gambar 11. Tampilan menu download

Dari tampilan program diatas dapat disimpulkan bahwa setiap pelaksaanaan kegiatan PPKH di Kabupaten Agam sudah dapat diimplementasikan dan digunakan agar hasil yang diharapkan sesuai dengan harapan agar dapat membantu masyarakat yang berada di Kabupaten Agam.

\section{SIMPULAN}

Yang dapat diambil kesimpulan dari Sistem Informasi PPKH Kabupaten Agam berikut ini yaitu dengan adanya Sistem Informasi PPKH Kabupaten Agam ini, setiap kegiatan-kegiatan pendamping dilapangan sudah dapat dipublikasikan pada jaringan internet agar informasi tentang PKH lebih efektif dan akurat. Selain itu, sistem informasi PPKH Kabupaten Agam dibuat dengan bahasa PHP dan dabase MySQL, dapat menyimpan file dokumen dan foto yang diupload apabila sewaktu-waktu dibutuhkan.

Berdasarkan kesimpulan yang diuraikan sebelumnya, maka dapat dikemukakan beberapa saran yang diharapkan menjadi bahan pertimbangan dengan harapan agar berguna bagi yang menggunakan sistem ini yaitu PPKH Kabupaten Agam diharapkan dapat mengembangkan aplikasi ini dengan menyesuaikan perkembangan teknologi saat ini.Siapapun yang berminat untuk menyempurnakan sistem ini, disarankan untuk menggunakan fitur pengelolaan data PKH yang lebih beragam

\section{DAFTAR PUSTAKA}

Alim, F. Y. (2019). Jurnal Ilmiah Administratie. Jurnal Ilmiah Administratie, 12(1).

Alsukri, S. (2020). Implementasi Program Keluarga Harapan (Pkh) Terhadap Keluarga Penerima Manfaat (Kpm) Di Kota Pekanbaru. Jurnal Ilmiah Muqoddimah: Jurnal Ilmu Sosial, Politik Dan Hummanioramaniora, 4(1), 26. https://doi.org/10.31604/jim.v4i1.2020.26-33

Bathin, M. S., \& Ramayanti, D. (2019). SOBATHUNI: Aplikasi Rumah Sewa Berbasis Web. Jurnal Edukasi Dan Penelitian Informatika (JEPIN), 5(2), 183. https://doi.org/10.26418/jp.v5i2.30452

Elmawati, Wedyawati, V., \& Sari, Y. (2020). Perancangan Sistem Informasi Data Rekam Medis Puskesmas Kumanis Kabupaten Sijunjung Dengan Menggunakan Bahasa Pemrograman Visual Basic.Net. Jurnal Sains Dan Teknologi: Jurnal Keilmuan Dan Aplikasi Teknologi Industri, 20(1), 1. https://doi.org/10.36275/stsp.v20i1.193

Irawan, A., Risa, M., M, M. A., S, A. E., Informatika, M., Banjarmasin, P. N., Bisnis, A., \& Banjarmasin, P. N. (2017). 4) 1,3,4. 3(2), 74-82.

Melinda, M., Borman, R. I., \& Susanto, E. R. (2017). RANCANG BANGUN SISTEM INFORMASI PUBLIK BERBASIS WEB ( STUDI KASUS: DESA DURIAN KECAMATAN PADANG CERMIN KABUPATEN PESAWARAN ) jurnal TEKNO 
KOMPAK vol.11, No.1.2017, 1-4 ISSN 1412-9663. 11(1), 1-4.

Vincensius, D., \& Wasito, B. (2017). Analisis Dan Perancangan Sistem Informasi Point of Sales Pada Cv . Sanjaya Abadi. Journal of Chemical Information and Modeling, 53(9), 1689-1699.

Wedyawati, V. (2019). Perancangan Aplikasi Cadangan Counter Check-in Lion Air Padang Dengan Menggunakan Bahasa Pemrograman Visual Basic 6.0. Jurnal Sains Dan Teknologi: Jurnal Keilmuan Dan Aplikasi Teknologi Industri, 19(1), 29. https://doi.org/10.36275/stsp.v19i1.124 